\title{
Multi-decadal climate variability as triggers of societal regime shifts in Japan
}

Takeshi Nakatsuka

\section{The PAGES Asia2k summer temperature reconstruction since 800 CE is providing valuable insights into Japanese} history. We demonstrate that multi-decadal temperature variability is closely associated with famines and warfare in Japan, resulting in significant societal changes.

Japanese historians have frequently remarked that climate may have had a significant impact on historical events, but have not reached a consensus on the mechanisms of change. A major challenge has been the use of different paleoclimate data based on a range of natural proxies, which were sometimes incorrect or contradictory to one another. In many instances, time series of past climate were arbitrarily selected by historians to support specific arguments. Of particular concern has been the inclusion and recognition of low-quality paleoclimate data for the robust analysis of climate and history relationships in Japan.

\section{The Asia2k reconstruction}

The PAGES 2k Network has successfully reconstructed annual changes in continental temperature by integrating many climate-sensitive proxy data over the past 2000 years (PAGES $2 \mathrm{k}$ consortium 2013). The strategy to use available data sets with strict selection criteria has helped make more reliable reconstructions. As part of this effort, the Asia2k Working Group has compiled more than 200 tree-ring chronologies beginning before $1600 \mathrm{CE}$ over a wide region in Asia (east of $70^{\circ} \mathrm{E}$ ), enabling the development of yearly summer temperature variations in individual grid points since 800 CE. Crucially, an average East Asia summer temperature reconstruction has been generated across all $2^{\circ}$ grid points north of $23^{\circ} \mathrm{N}$ (Cook et al. 2013). Although the original treering chronologies are mainly distributed in inland cold regions, such as Tibet, Himalaya and Mongol, the reconstructed temperature variation corresponds well to the summer temperature index during early modern Japan (Fig. 1A) estimated from documentary records of climate disasters (Maejima and Tagami 1986). Because tree-ring based temperature reconstructions have typically been limited to the last 500 years in Japan, the new Asia2k paleo-temperature data enables us, for the first time, to elucidate climate and history relationships at annual time scales for medieval and ancient Japan before 1500 CE.

Apparent coincidence to Japanese history Multi-decadal variability in the East Asia summer temperature appears to have been enhanced during the 12-15th centuries in medieval Japan, and was associated with numerous famines and wars which culminated in the Sengoku period, characterized

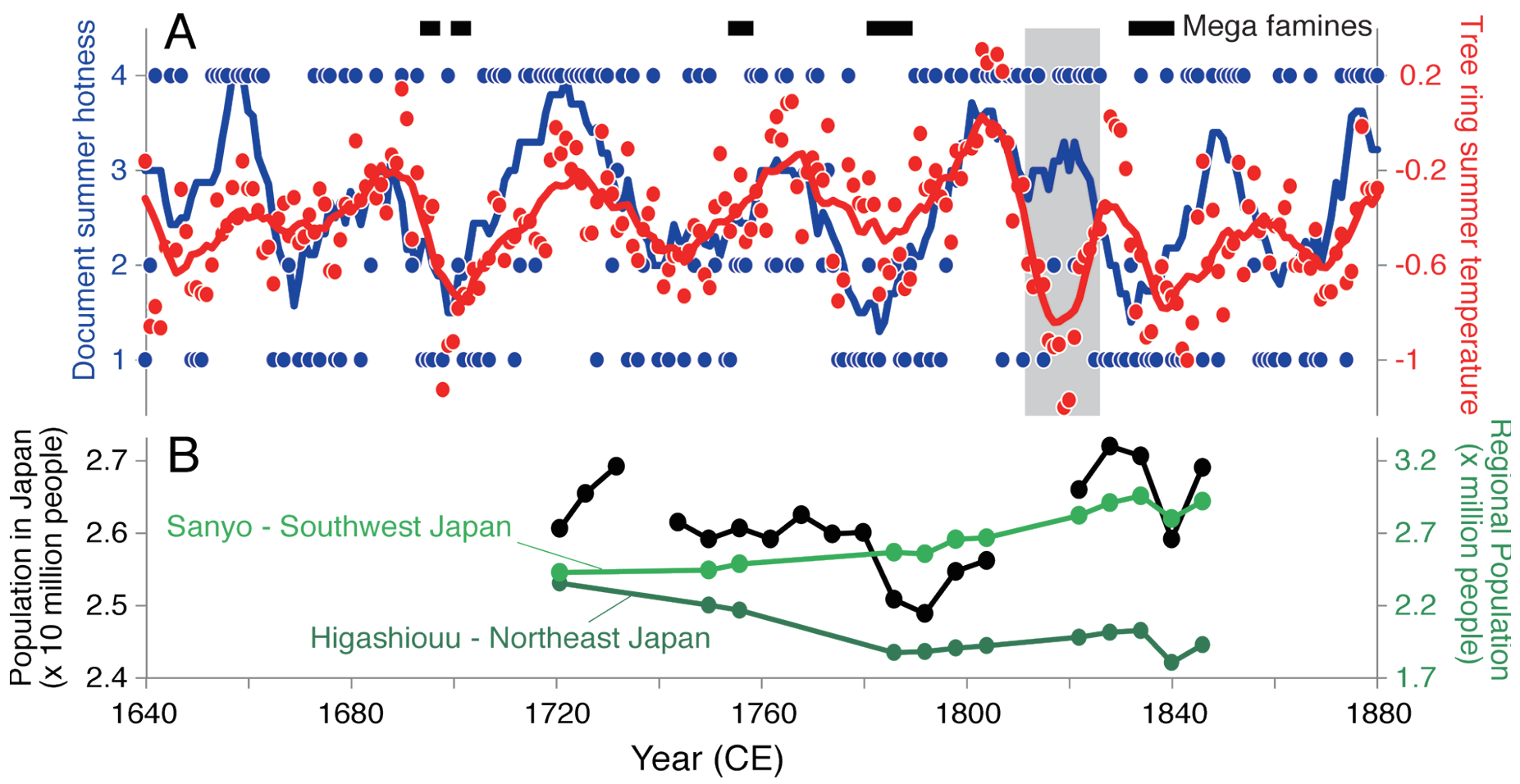

Figure 1: (A) Tree-ring based East Asia summer temperature reconstruction (red; Cook et al. 2013) and document-based Japanese summer hotness estimation (blue; Maejima and Tagami 1986) during 17-19th centuries. Solid circles and thick curves show annual and 11 years running mean values, respectively. Except for the extremely cold winter of 1820 CE (gray shade), both time-series parallel one another closely. Upper black thick lines indicate occurrence of mega famines in northeast Japan. (B) Populations in Japan (black solid) and two regions (green). 


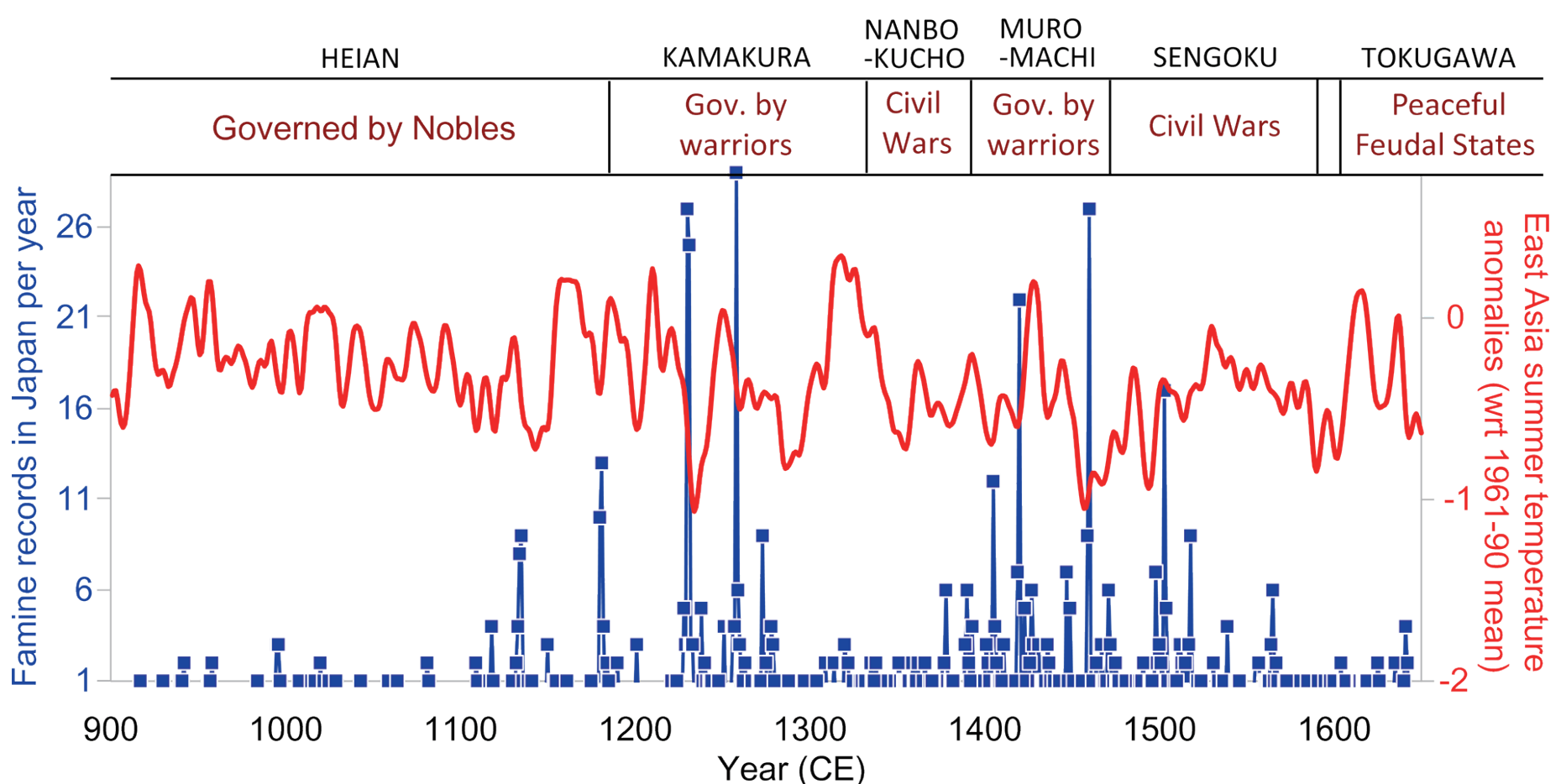

Figure 2: Number of documentary records of famine per year in Japan (blue; Fujiki 2007) and 11-year running mean of East Asia summer temperature (red; Cook et al. 2013). Upper panels define key historic periods (black: name of era; brown: political characteristics).

by near-constant warring states and societal unrest in the 16th century (Fig. 2). The comparison between temperature and historical events demonstrates that abrupt cooling after 10-20 years of long warmth often caused famines characterized by unprecedented numbers of deaths (Fig. 2) and sustained periods of warfare. Because pre-modern Japanese societies were based on rice paddy cultivation, the increase in rice yields during the warm period might have led to overpopulation, resulting in a society poorly prepared for the following cold period and the inevitable decline in agricultural yields. An example is the Kangi mega-famine in 1230-1231 CE, caused by the abrupt drop in summer temperature after several decades of unprecedented warmth from the middle of the 12th century. Another example is the Kansho famine of 1459-1460 CE, which led to the Onin war (1467-1477 CE), the destruction of the capital city Kyoto, and ultimately led to Japan becoming an aggregate of warring states. Overall, multi-decadal temperature variability from the 12-15th centuries appears to have resulted in many serious societal disturbances, with political government led by nobles during periods of relatively stable climate, followed by civil wars and warrior leadership during subsequent climate instability. It therefore seems that temperature variability was a major driver of societal regime shifts.

The cause-and-effect relationship between multi-decadal climate variability and societal responses can also be observed in the early modern period (17-19th centuries; Fig.1).

During the bi-decadal warmth around 1720 and $1800 \mathrm{CE}$, rice yields rose and population increased even in cold northeast Japan, where rice normally grew poorly under average climate. Local people in northeast
Japan became involved in the national rice market, selling excess rice and raising capital to support the finance of local lords and improve the living standard of peasants. These sustained warm conditions thus made adaptation to abrupt cooling difficult, tragically resulting in famines. When the climatic situation changed and famines occurred, the people in Japan started to rebel against the Tokugawa government. Although the Tokugawa government suppressed rebellions at that time, the frequent famines in northeast Japan led to geographical balance change in population and economy (Fig. 1B), leading to a "stronger" southwest region and the reformation of government in $1868 \mathrm{CE}$ conducted by the people from the southwest Japan.

\section{Paleodata for historical studies}

The above-mentioned examples for the apparent coincidences between climate changes and historical events in medieval and early modern Japan are, however, special cases. In fact, modes of societal responses to climate change differed depending on the region and period they took place. Abrupt cooling in medieval Japan often caused famines, but we cannot find many indications of famines during the 14th century in historical documents (Fig. 2). While famines directly resulted in war in the late 15th century, they did not cause war in the 13th century. In some feudal domains of northeast Japan during the 18th century, local lords could save people from starving, even when a famine, due to crop failure, killed several hundred thousand people in total over northeast Japan (Fig.1).

As a result, we find there are many lessons embedded in history of societal adaptability to climate change. To date, however, historians have been limited in their ability to critically assess past societal responses to climate changes, because previous studies on human history have not had access to robust paleoclimate data such as that generated by Asia2k. Crucially, we can now learn from past societal struggles to overcome climate disasters by precisely comparing paleoclimate data with the enormous historical and archeological evidence available in Japan. Our results suggest this is a promising way for the promotion of new inter-disciplinary studies between humanity and natural sciences, contributing to the strategy of Future Earth. In Japan, an inter-disciplinary research project "Societal adaptation to climate change: Integrating paleoclimatological data with historical and archaeological evidences" (www.chikyu.ac.jp/ rihn_e/project/H-05.html) is now ongoing, to take advantage of the full potential of paleoscience.

\section{AFFILIATIONS}

Research Institute for Humanity and Nature, Kyoto, Japan

\section{CONTACT}

Takeshi Nakatsuka: nakatsuka@chikyu.ac.jp

\section{REFERENCES}

Cook ER et al. (2013) Clim Dyn 41: 2957-2972

Fujiki H (2007) "Chronological Table of Medieval Climate Disaster" (in Japanese)

Maejima I, Tagami Y (1986) Geog Rep Tokyo Metro Univ 21: 157-171

PAGES 2k consortium (2013) Nature Geosc 6: 339-346 